\title{
NUMERICAL ANALYSIS OF THE EXPERIMENTAL FLAT SLAB FOR THE PARAMETRICAL STUDY
}

\author{
L. Majtánová*, J. Halvonik**
}

\begin{abstract}
Reinforced concrete flat slabs are frequently used structural members in building construction. One of the most dangerous form of structural failure of these system is punching of the slab by column. Two experimental slab specimens reinforced with a high amount of shear reinforcement that increased punching resistance over the concrete struts capacity were tested. The best way how to verify the reliability of standard model for the assessment of punching capacity is comparison of the resistance obtained from the experiments, with the resistances calculated according to the standard. To determine the reliability of the standards a large database of test results is required. However, from economical point of view, it is not possible to prepare so many tests in order to fulfill this requirement. The problem can be solved by non-linear analysis which is a tool that allows to substitute actual tests with theoretical ones. The paper deals with calibration of the numerical model of flat slab specimens using results taken from the experimental program. The task was to find the suitable nonlinear material model for concrete and reinforcement, choose the proper boundary conditions and the correct load application. The correct adjustment of the numerical model allows to carry out parametric study of flat slabs with shear reinforcement.
\end{abstract}

\section{Keywords: flat slab, non-linear analysis, punching, studs, concrete strut capacity}

\section{Introduction}

Flat slabs are one of the most widely used structural system for construction of administrative buildings nowadays. Together with many advantages connected particularly with architecture and construction processes, the system possesses also some drawbacks. From structural point of view, the most dangerous is concentration of shear forces at the vicinity of columns which may cause punching of a slab. Such damage is usually associated with very small deformations and crack widths prior to failure and, as such, can occur without noticeable warning signs. Local failure in one column area may spread all over the structure with terminal stage progressive collapse of the whole structure. In order to improve structural behavior and to increase punching capacity the transverse reinforcement is used. Application of transverse reinforcement allows for significant increment of punching shear resistance in comparison with flat slabs without this reinforcement and the failure has more ductile mode.

\section{Experimental program}

Two flat slab specimens with shear reinforcement (S1-1 and S2-1) and with dimensions of $2.5 \times 2.5 \times 0.25$ $\mathrm{m}$ were tasted in laboratory of Slovak University of Technology. Slabs were reinforced by bending reinforcement $\varnothing 20 / 100 \mathrm{~mm}$ and were supported on columns with diameter of $180 \mathrm{~mm}$. Columns were confined by spiral reinforcement and steel tube in order to reach higher axial resistance. These specimens were reinforced by transverse reinforcement consisting of double headed Peikko PSB studs with diameter of $10 \mathrm{~mm}$ from B500B steel. During the experimental works, the specimen was loaded with hydraulic jack located under the column. The specimen was tied up to the strong floor of the laboratory with 8 steel rods.

\footnotetext{
Ing. Lucia Majtánová, PhD.: Slovak University of Technology, Faculty of Civil Engineering; Radlinského 11, 81005 Bratislava, SR, lucia.majtanova@stuba.sk

** Prof. Ing. Jaroslav Halvonik, PhD.: Slovak University of Technology, Faculty of Civil Engineering; Radlinského 11, 81005 Bratislava, SR, Jaroslav.halvonik@ stuba.sk
} 
Slabs were loaded under axis-symmetric conditions. Load was measured by load cell with the capacity of 2000 kN. In Fig. 1: are shown dimensions of experimental specimens and lay-out of the experiment.
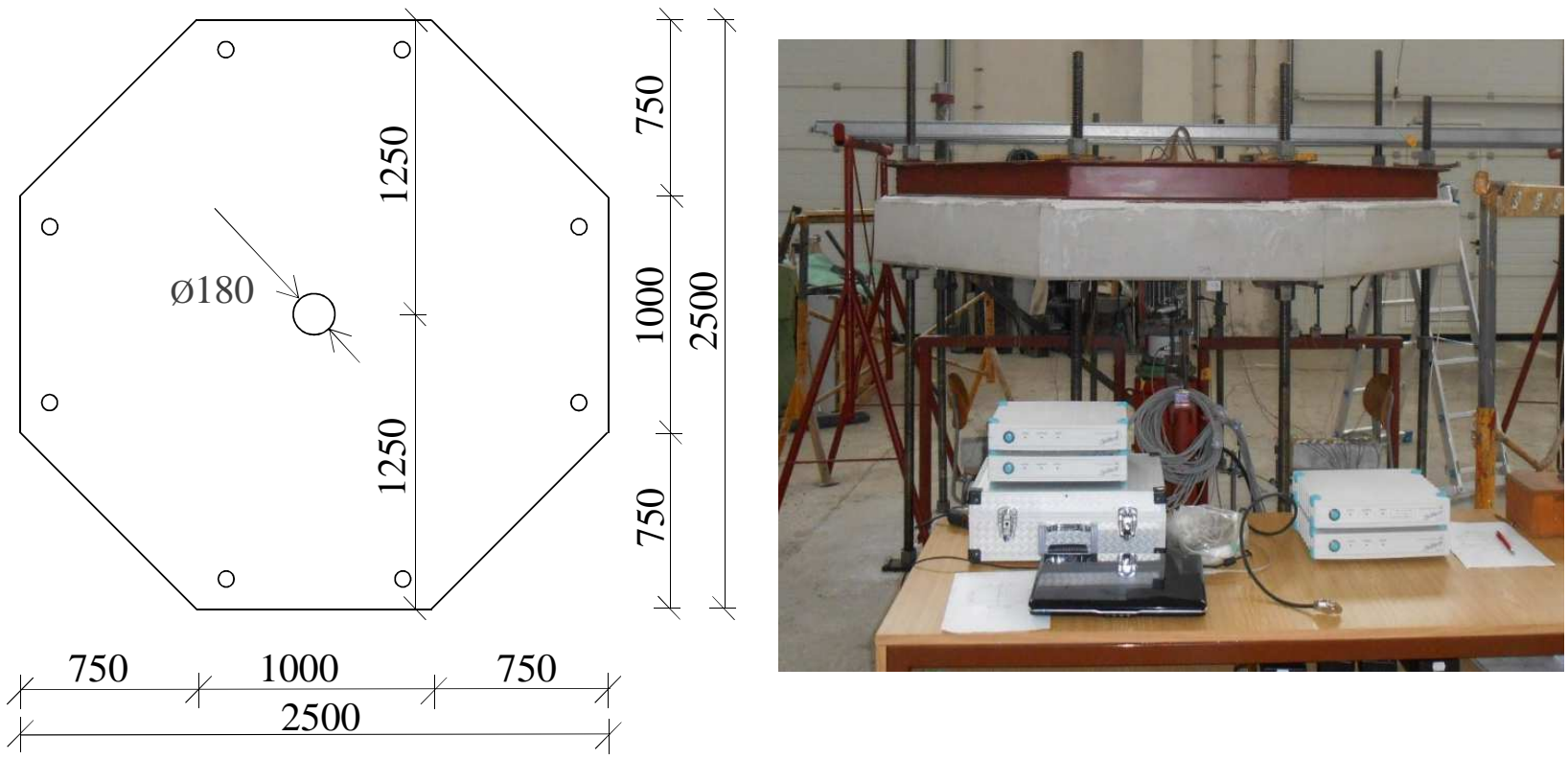

Fig. 1: Left: slab dimensions. Right: lay-out of experiment.

\section{Numerical model of the experimental flat slab}

Fig. 2: shows the numerical model in FEM software SOFiSTiK and model represents the real experimental program according chapter 2. For non-linear analysis, slab S2-1 was selected because this specimen contained shear studs symmetrically stored, and symmetry was important in modeling and meshing. For the concrete modeling tetrahedron bricks with the elastic-plastic material model according to LADE with non-associated flow rule were used. The shear studs and reinforcement (in column and slab) was modelled using 1D elements with stress-strain diagram of typical reinforcing steel. The model was meshed automatically.
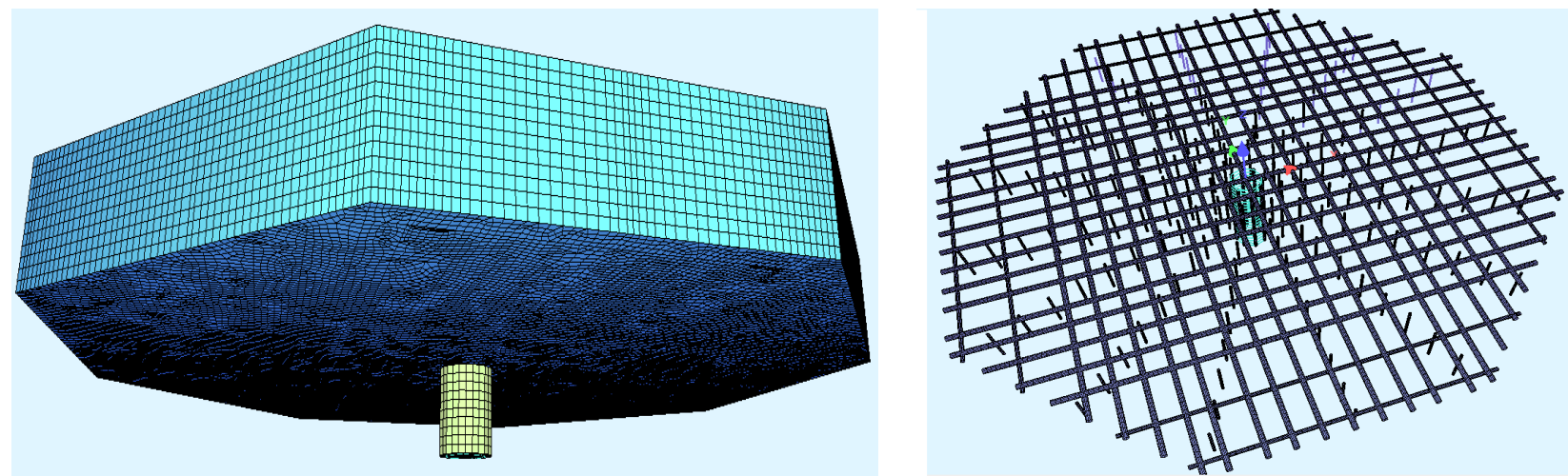

\section{Fig. 2: Numerical model of flat slab. Left: model of concrete tetrahedron bricks. Right: model of bending} and shear reinforcement in FEM software SOFiSTiK.

Important parameters of the materials and results of the tests for numerical analysis are introduced in Tab. 1 :, where $f_{\mathrm{cm}}$ is mean value of cylinder compressive strength of concrete, $E_{\mathrm{cm}}$ is modulus of elasticity, $f_{\mathrm{ym}}$ is mean value of yield strength, $n_{\mathrm{st}}$ is number of studs in one ring around column, $V_{\mathrm{R} \text {,test }}$ is the punching shear resistance of test specimens and $w$ is the maximum deflection. All material parameters were tested in laboratory of Slovak University of Technology. Reference load of the FEM analysis was $1500 \mathrm{kN}$, which represent higher force than from test obtained punching capacity. The load was applied to the bottom 
column area as a uniformly distributed load $\left(58947 \mathrm{kN} / \mathrm{m}^{2}\right)$. Dynamic calculation with time steps without dynamic damping was used. Each time step followed the previous one, used as primary load case applied to the elements with modified stiffness and stress state from previous step. Number of the time steps was selected as 15 and each time step lasted 100 seconds.

Tab. 1: Important material properties and test results

\begin{tabular}{cccccccc}
\hline Slab & $f_{\text {cm }}[\mathbf{M P a}]$ & $\boldsymbol{E}_{\mathrm{m}}[\mathbf{M P a}]$ & $\boldsymbol{f}_{\mathrm{ym}}[\mathbf{M P a}]$ & studs & $\boldsymbol{n}_{\text {st }}$ & $\boldsymbol{V}_{\mathrm{R}, \text { test }}[\mathrm{kN}]$ & $\boldsymbol{w}[\mathbf{m m}]$ \\
\hline $\mathrm{S} 1-1$ & 38.2 & 32520 & 577.5 & Yes & 15 & 1520 & 25.05 \\
\hline $\mathrm{S} 2-1$ & 28.1 & 35630 & 538.1 & Yes & 16 & 1250 & 22.90 \\
\hline
\end{tabular}

The diagram, shear force - deformation, in Fig. 3:, represents comparison of the results from numerical model and experimental test. The red line (symbol $\mathbf{\Delta}$ ) indicates the actual results from experimental program. Obtained punching resistance was $1250 \mathrm{kN}$ accompanied with deflection of $22.9 \mathrm{~mm}$. The blue line (symbol $\mathbf{a}$ ) represents calibrated numerical model with real boundary conditions and modeled column with reinforcement. The gray line (symbol $\bullet$ ) represents simplified numerical model where real support (column) was replaced by steel plate.

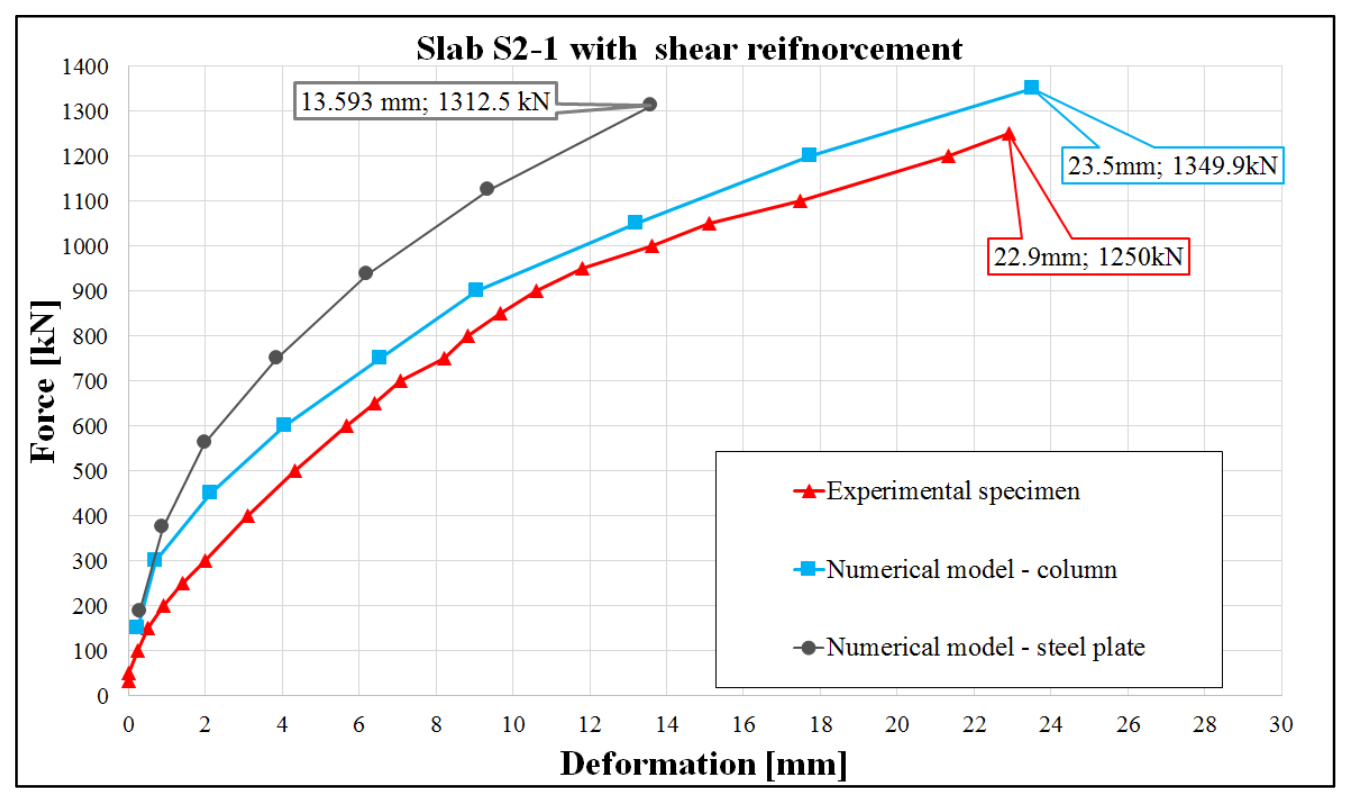

Fig. 3: Comparison of the deformation in the middle of the slab

In Fig. 4 is shown cut saw experimental specimen after damage. Specimen failed when column started to penetrate slab and crashed concrete dropping out at column periphery has been observed. It can be seen in Fig.4 also crushed of the concrete strut around the column.

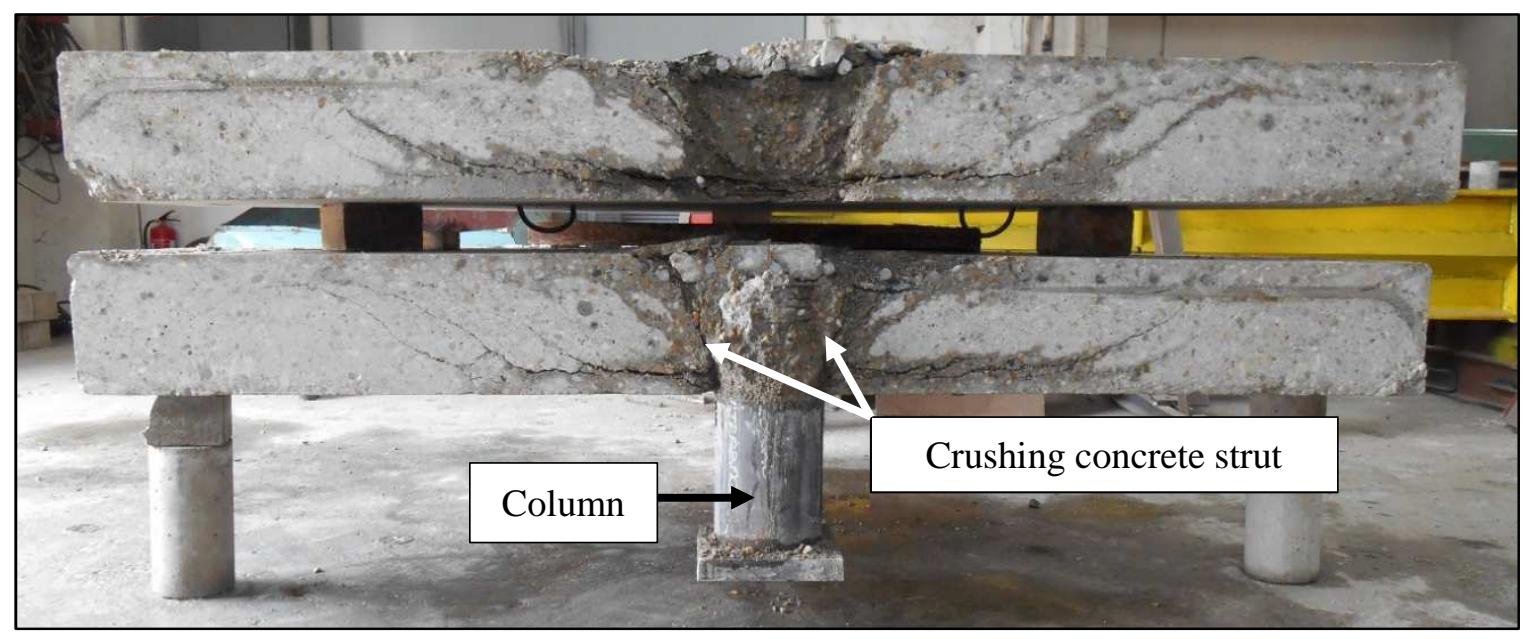

Fig. 4: Cut saw specimen after damage due to crushing compressive diagonal 
In Fig.5 is shown the specimen after damage in numerical model. We can see that form of the damage is comparable with actual one. The failure was caused by crushing of concrete at the vicinity of the column. Numerical analysis confirmed that crushing of the concrete struts can be governing mode of failure of a flat slab reinforced by transverse reinforcement.

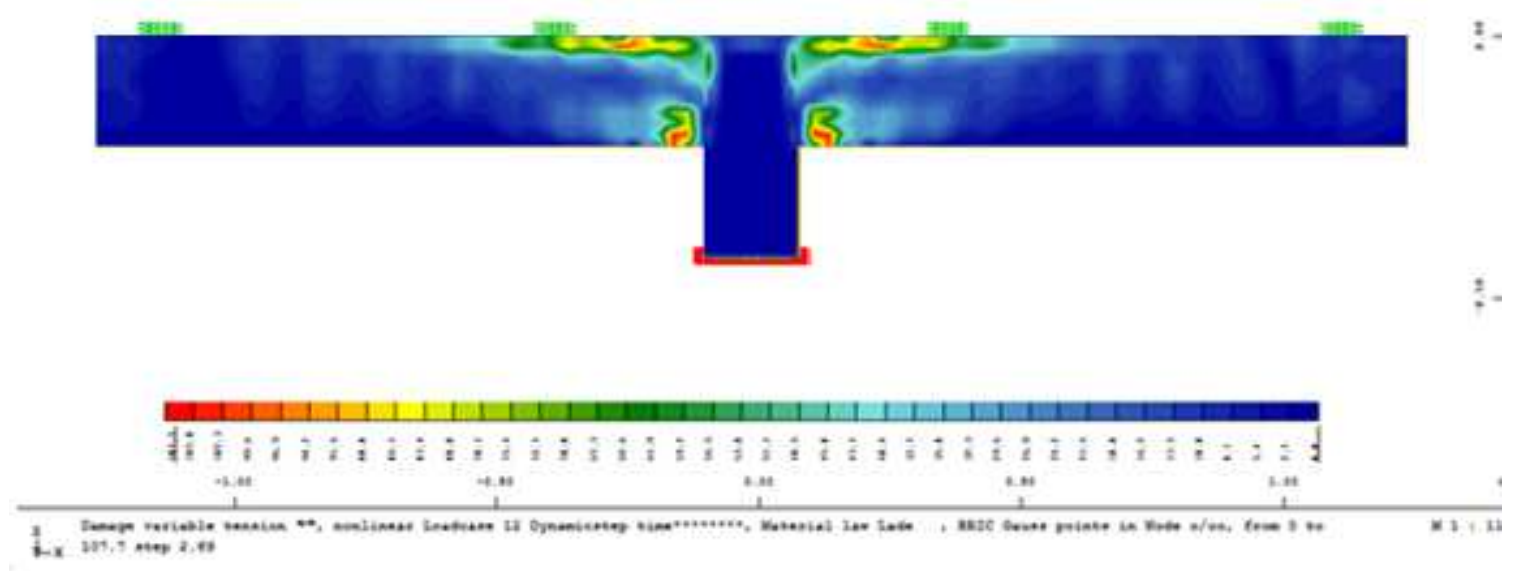

Fig. 5: Specimen after damage in numerical model.

\section{Conclusions}

In this work are presented some problems regarding the reinforced concrete flat slabs. After series of experiments, the numerical model was calibrated according to the obtained test results. The main goal of the analysis was to match behavior, deflection and resistance in the highest possible accuracy. In numerical model, two different methods of support were used and the result demonstrated the importance of modeling of real the boundary conditions. The difference between punching capacity obtained from numerical analysis and test was $7.9 \%$ and it was accompanied with deflection difference only $2.5 \%$. The higher difference in punching resistance was probably caused by the not perfect axis-symmetric conditions during the test. Change of the column support to the steel plate led to the punching difference 5\%, however, difference of deflection difference increased up to $40 \%$. The obtained results indicate sensitivity of nonlinear models on the way of load application and boundary conditions.

In the next steps, the authors plan to compare strain in concrete and reinforcement too. In the future we would like to prepare parametrical study where some input parameters will be changed.

\section{Acknowledgement}

This work was supported by Scientific Grant Agency of the Ministry of Education, science, research and sport of the Slovak Republic and the Slovak Academy of Sciences No 1/0810/16 and by the Slovak Research and Development Agency under the contract No. APVV-15-0658.

The authors would like to thank also to Kamil Laco from the company M \& P, spol. s r.o. for the help and technical support.

\section{References}

Ebrahimian, H., Astroza, R., Conte, J. P, Restrepo, I. J. and Hutchinson, C. T. (2016) Pre-test Nonlinear Finite Element Modeling and Response Simulation of Full-Scale Five-Story Reinforced Concrete Building Tested on NEES UCSD Shake Table, California Institute of Technology, Suisse, July 2016.

Einpaul, J., Bujnak, J., Ruiz, M., and Muttoni, A. (2016) Study on influence of column size and slab slenderness on punching strength, ACI Structural Journal, V. 113, pp.135-145

EN1992-1-1 Design of Concrete Structures, Part 1-1 General Rules and Rules for Buildings, May 2004

Genikomsou, A.S. and Polak, M.A. (2017) Effect of Openings on Punching Shear Strength of Reinforced Concrete Slabs - Finite Element Investigation, ACI Structural Journal, Vol 114, 5, pp. 1249-126.

Muttoni, A. and Ruiz, F. (2017) Provisions for shear and punching shear, 8th draft, Presentation from CEN/TC250/SC2/WG1/TG4 meeting in Amsterdam, 24. March 2017 